\title{
IMPLIKASIES \\ VAN DIE GRONDWET VIR GESONDHEIDSDIENSTE
}

\section{REFERAAT GELEWER BY DIE VERPLEGINGSFORUM VAN DIE SA VERPLEEGSTERSVERENIGING, MAART 1984. Dr J P Roux}

\section{INLEIDING}

Die nuwe Grondwet van die R S A bied nuwe uitdagings op die terrein van gesondheidsdienste. Vir die eerste keer sedert 1910 sal al die bevolkingsgroepe op die verskillende vlakke inspraak hê en kan deelneem aan besluitneming oor die lewering van gesondheidsdienste aan die bepaalde gemeenskappe waaraan hulle behoort.

Tergelykertyd moet daar egter rekening gehou word met die feit dat die ongesteldhede wat die bevolking van Suid-Afrika bedreig deur geen grense, hetsy etniese, geografiese of landsgrense aan bande gelê kan word nie. Dit maak doeltreffende koördinasie nieteenstaande die verskeidenheid van owerhede en dienste, van die grootste belang.

\section{ORGANISATORIESE REËLINGS}

Om die basiese beginsel van die nuwe Grondwet, naamlik selfbeskikking oor eie sake en medeverantwoordelikheid in algemene sake, sinvol toe te pas sal ingrypende organisatoriese reëlings op die terrein van gesondheidsdienste getref moet word. Daarmee saam moet 'n tweede belangrike beginsel van die nuwe Grondwet raakgesien word en dit is die beginsel van maksimale devolusie van bevoegdhede en desentralisasie van administrasie op plaaslike bestuursvlak en van minimum administratiewe beheer oor plaaslike owerhede.

\section{Uitvoerende Gesag}

Die kabinet met die President as Voorsitter sal uitvoerende gesag uitoefen oor gesondheidsake van algemene belang. Om die behartiging

\section{SUMMARY}

The new Constitution of the RSA presents new challenges in the field of health services. For the first time the various population groups will participate in decisions about delivery of health care to their own communities.

The diseases which affect the population of South Africa. however, do not have any ethnical or geographical boundaries. This necessitates effective co-ordination, despite the various authorities and services.

Administrative implications include greater privatisation of functions currently performed by the authorities, devolution of power to local authorities and co-ordination regarding health personnel administration.

For the allocation of finances for health services the author suggests a number of principles for the delivery of health services as well as priorities for long term spending.

Management ability of health personnel at all levels in order to meet the challenges of the new Constitution is also stressed.

van gesondheidsake van eie belang moontlik te maak sal daar 'n Ministersraad vir elkeen van die bevolkingsgroepe, Blankes, Kleurlinge en Indiërs, saamgestel word en elke Minister sal oor een of meer staatsdepartemente gesag uitoefen.

Wat gesondheid betref sal daar dus 'n Minister van Gesondheid met sy eie departement wees wat sake van gemeenskaplike belang administreer en drie Ministers van Gesondheid wat sake van eie belang administreer, elk met sy eie departement. Die vier ministers saam vorm die uitvoerende gesag met betrekking tot alle gesondheidsdienste in die $\mathrm{R} \mathrm{S} \mathrm{A.}$

Wat die administrasie van gesondheidsdienste betref sal daar in die praktyk gevolglik vier Departemente van Gesondheid wees. Om die nodige koördinasie te bewerkstellig, uitgawes tot 'n minimum te beperk en beskikbare mannekrag oordeelkundig aan te wend, behoort die vier departemente nie in isolasie van mekaar ingestel te word nie. Daar kan byvoorbeeld van een sentrale hoofkwartier gebruik gemaak word waar formulering van beleid en breë beplanning gekoördineer word.

Om te voldoen aan die beginsel van desentralisasie van administrasie sal daar noodwendig van 'n aantal streekorganisasies gebruik gemaak word, elk waarvan elemente van die betrokke vier departemente bevat. Hierdie streekorganisasies sal uitgebreide uitvoerende bevoegdhede moet ontvang met die voorwaarde dat administrasie van gesondheidsdienste op plaaslike bestuursvlak ongehinderd voortgesit kan word.

\section{Plaaslike owerhede}

Om volle uiting te gee aan die beginsels van selfbeskikking oor eie sake deur die verskeie groepe, maksimale devolusie van magte, desentralisasie van administrasie na die vlak van plaaslike owerhede en minimale administratiewe beheer oor plaaslike owerhede is dit duidelik dat 'n verskeidenheid van autonome eenhede, elk met sy besondere struktuur, mettertyd op gemeenskapsvlak moet ontwikkel. 
Daar desentralisasie die hoofkenmerk van die grondwetlike hervormings is, is dit miskien gepas om 'n paar definisies van nader te beskou. Desentralisasie kan beskryf word as die oordra van die gesag om te beplan, besluite te neem oor en administrasie van openbare funksies vanaf die sentrale regering na ondergeskikte regeringseenhede of ander instellings. Desentralisasie impliseer dus die oordraging van verskeie grade van outonomie, vertikaal sowel as horisontaal, aan ondergeskikte of ander eenhede van die gemeenskap. Drie definitiewe grade van desentralisasie na streke, gemeenskappe, kulturele of minderheidsgroepe kan geïdentifiseer word, naamlik:

- Dekonsentrasie wat administratiewe verskuiwing van werklading vanaf een sentrale punt na 'n aantal punte behels, sonder om aan die personeel die gesag te gee om te besluit hoe die funksies uitgevoer moet word. Dekonsentrasie is die swakste vorm van desentralisasie.

- Delegering impliseer die oordra van verskeie grade van besluitnemingsmagte omtrent die beplanning en implementering van regeringsbeleid aan organisasies wat tegnies en administratief in staat is om dit uit te voer.

- Devolusie is die uiterste vorm van desentralisasie en kom neer op die skep van relatief onafhanklike vlakke of eenhede van regering met finale besluitnemingsmagte.

In die praktyk sal dit neerkom op devolusie van sommige van die magte wat nog dié van die eerste en tweede vlakke van die regering is aan plaaslike owerhede. Plaaslike owerhede sal natuurlik mettertyd ook groter wetgewende en uitvoerende magte met betrekking tot die lewering van gesondheidsdienste moet kry.

Miskien moet kortliks na die huidige situasie gekyk word. Nuwe regulasies tree op 1 April 1984 in werking ten opsigte van die voorwaardes verbonde aan die betaling van subsidies aan plaaslike owerhede ingevolge artikel 26 van die Wet op Gesondheid vir die lewering van sekere gesondheidsdienste.
Hierdie dienste word in 'n aantal basiese kategorieë ingedeel soos:

- omvattende gesondheidsdienste (primêre gesondheidsorg)

- hospitalisasie van tuberkulose pasiënte

- maatreëls teen voedingsgebreksiektes

- gesinsbeplanningsdienste

- omgewingsdienste.

Twee areas kan tans aandag kry met die oog op die uitbreiding van uitvoerende verantwoordelikheid. Eerstens, die insluiting van Artikel30 gebiede, onder die beheer van bestaande plaaslike owerhede. Hier word verwys na die gebiede buite die regsgebied van statutêre plaaslike owerhede in die Transvaal, Oranje-Vrystaat en Natal. Tweedens, moet die verskaffing van 'n omvattende hospitaalsentriese gesondheidsdiens vanaf gemeenskapshospitale deur streeks-plaaslike owerhede ondersoek word.

In Bylae 1 van die Grondwet word plaaslike bestuur binne 'n groepsgebied as 'n eie saak beskryf en word die beginsel van selfbeskikking oor eie sake en medeverantwoordelikheid in algemene sake ten opsigte van plaaslike bestuur bevestig.

Hoewel die Grondwet self nie verder op die saak ingaan nie is voorsiening gemaak vir die verdere uitbouing van plaaslike besture in die Wet op die Bevordering van Plaaslike Owerheidsaangeleenthede en Munisipale Ontwikkelingsrade. die Raad vir die Koördinering van Plaaslike Owerheidsaangeleenthede en Munisipale Ontwikkelingsrade.

Dit word in die vooruitsig gestel dat plaaslike besture, wat daartoe in staat is of mettertyd deur die totstandkoming van metropolitaanse gesondheidsowerhede en landelike streekrade daartoe in staat gestel word, volle verantwoordelikheid vir die lewering van alle gesondheidsdienste in hulle gebied behoort te aanvaar. Hierin lê die uitdaging van die toekoms omdat ' $n$ veelvoud van kombinasies moontlik is, altyd met inagneming van die beginsel van selfbeskikking oor eie sake en medeverantwoordelikheid in algemene sake.
Die lewering van 'n hospitaalsentriese gesondheidsdiens met primêre gesondheidsorg as uitgangspunt en hoogste prioriteit, op 'n gekoördineerde wyse, maar onderworpe aan algemene gesondheidsbeleid en wetgewing, sal die ideale toestand skep. Dit sal deelname aan besluitneming op plaaslike vlak en betrokkenheid by gesondheidsake moontlik maak. So 'n stap sal egter gepaard moet gaan met die daarstelling van 'n sterk streekgesondheidsorganisasie wat alle gesondheidsdienste - kuratief, voorkomend, bevorderend en rehabiliterend - in die betrokke streek sal koördineer en administreer.

\section{ADMINISTRATIEWE IMPLIKASIES}

\section{Formulering van \\ Gesondheidsbeleid}

Een van die beginsels van die nuwe Grondwet is om aan Blankes, Kleurlinge en Indiërs die reg te verleen om afsonderlik oor eie sake van hulle betrokke bevolkingsgroepe te besluit. Maatstawwe vir die bepaling van gesondheidsaangeleenthede wat van eie aard is word in Artikel A (1) van die nuwe Grondwet aangedui en word hoofsaaklik toegespits op aangeleenthede wat die bevolkingsgroep met betrekking tot behoud van sy identiteit en die handhawing en bevordering van sy lewenswyse, kultuur, tradisies en gebruike spesiaal of afsonderlik raak.

Dit is ook belangrik om in gedagte te hou dat die owerheidsinstelling wat die belange van die betrokke bevolkingsgroep behartig, nie deur die bepaling van die aard van die diens in staat gestel word om die belange van enige ander bevolkingsgroep (nadelig) te raak nie.

In Bylae 1 van die nuwe Grondwet word ten opsigte van gesondheidsdienste aangedui wat met die onderwerpe in artikel 14 bedoel word. Bylae 1 verwys na Gesondheidsaangeleenthede wat die volgende omvat naamlik -

- hospitale, klinieke en soortgelyke of verwante inrigtings

- geneeskundige dienste by skole en aan behoeftiges

- gesondheids- en voedingsvoorligting 
- die registrasie van en beheer oor private hospitale,

maar onderworpe aan enige algemene wet oor sodanige aangeleenthede. In die Verklarende Memorandum oor die Grondwet word die volgende bygevoeg:

as hierdie aangeleenthede egter nie net op 'n spesifieke bevolkingsgroep betrekking het nie, maar meer as een groep raak, sal hulle algemene sake wees.

In die bepaling van die eie of algemene aard van 'n gesondheidsdiens sal ander kriteria, soos die geografiese ligging van hospitaal of kliniek en toekomstige beleid ten opsigte van enige bepaalde inrigting, ook in ag geneem moet word.

Artikel 93 verwys na die Administrasie van Swart Sake. In die Verklarende Memorandum word aangedui dat die huidige bepaling met betrekking tot die Staatspresident se beheer oor en administrasie van sake wat Swartmense raak uit die Grondwet 1961, oorgeneem word. Dit beteken in die praktyk dat die spesiale magte wat die Staatspresident met betrekking tot Swartmense uitoefen, wat onmiddellik voor die inwerkingtreding van die nuwe Grondwet by hom berus het, by hom bly berus met al die bevoegdhede wat hy in verband daarmee besit.

Aangesien die spesiale magte by die President berus kan die afleiding gemaak word dat enige diens wat Swartmense se identiteit en belange direk of indirek raak, nie as 'n eie saak vir enige van die ander drie bevolkingsgroepe geklassifiser kan word nie. Hierdie begrip hou belangrike implikasies in, want dit spreek vanself dat enige hospitaal of kliniek waar Swartmense bedien word nie as 'n eie saak beskou kan word nie, behalwe in gevalle waar daar 'n spesiale uitsondering gemaak word.

Die Wet op Swart Plaaslike Besture, No 102 van 1982 is hier van besondere belang aangesien daar reeds ongeveer 'n dertigtal outonome Swartrade in die R S A ingestel is wat eersdaags as volwaardige plaaslike besture sal funksioneer.

Die begrip kliniek moet miskien beter omskryf word. Daar moet verkieslik na 'n primêre gesondheidsorg-dienspunt verwys word aangesien daar ook in baie gevalle tuisbesoeke afgelê word deur verpleegkundiges en daar mag ook mobiele klinieke of dienspunte wees. In die algemeen kan aanvaar word dat in geval van 'n vaste dienspunt of mobiele kliniek wat

- hoofsaaklik een bevolkingsgroep bedien en

- geografies binne die gebied van jurisdiksie van 'n bepaalde bevolkingsgroep geleë is of beweeg

as 'n diens van eie aard beskou kan word en aan die betrokke Kamer toegeken moet word.

Wat gesondheidsvoorligting betref behoort aspekte van algemene aard soos publikasies en brosjures oor siektetoestande, bevordering van gesondheid en voorkoming van siektes, as 'n saak van algemene belang beskou te word. Waar voorligtingsdienste deur voorligters onder 'n bepaalde bevolkingsgroep gelewer word kan dit as 'n saak van eie aard beskou word.

Die regering se verklaarde beleid van privatisering van owerheidsaktiwiteite kom daarop neer dat funksies wat nie noodwendig deur die openbare sektor uitgevoer hoef te word nie na die privaatsektor oorgedra moet word. Dit bou voort op die beginsel dat mense so ver doenlik self moet besluit oor gesondheidsake wat hulle raak.

\section{Privatisering van owerheidsfunksies}

Dit is miskien nodig om op hierdie vroeë stadium reeds die aandag te vestig op ' $n$ belangrike riglyn wat in die nuwe Grondwet na vore kom, naamlik dat private inisiatief en effektiewe mededinging bevorder moet word, ook wat gesondheidsfunksies betref. Een van die belangrikste redes hiervoor is die feit dat daar 'n toenemende getal betalende pasiënte wat aan mediese skemas behoort onder alle bevolkingsgroepe voorkom en dat die privaatsektor in 'n land waar vrye ondernemerskap aangemoedig word sy verantwoordelikheid vir die mediese versorging van sy werknemers sal moet aanvaar.
In hierdie verband behoort privatehospitale in gebiede waar daar 'n tekort aan beddens is, en losstaande teatereenhede en selfs ook gemeenskapsgesondheidsentrums (GGS) deur die privaatsektor opgerig te word om sodoende die druk op Staatshospitale te verlig. Waar die staat self 'n GGS oprig bestaan daar werklik geen rede waarom die staat en die privaatsektor nie gesamentlik 'n gesondheidsdiens kan lewer nie, wat beide kuratiewe en voorkomende dienste sal insluit.

'n Ander terrein waar die privaatsektor en veral private industrie hulle deel kan bydra is byvoorbeeld die bekamping van 'n siekte van nasionale belang soos tuberkulose. As 'n werknemer aan 'n siekefonds behoort is daar geen rede waarom verantwoordelikheid vir die behandeling van 'n aansteeklike siekte soos tuberkulose nie by dié van ander siektes ingesluit kan word nie.

Die Staat sal steeds verantwoordelik bly vir die behandeling van behoeftiges, afgesien van die tipe ongesteldheid waaraan daar aandag geskenk moet word. Dit is een aspek waar plaaslike besture in die toekoms 'n groter rol sal moet vervul omdat die eiesoortige behoeftes van elke gemeenskap op plaaslike vlak bekend is en aandag sal geniet.

\section{Strukturele/Organisatoriese Implikasies}

- Die beleid van privatisering van owerheidsfunksies en die oordrag van funksies na die privaatsektor sal noodwendig strukturele verandering tot gevolg hê.

- 'n Tweede aspek wat hier ter sprake is, is die afwenteling van funksies wat tans deur staatsdepartemente en provinsiale administrasies verrig word na plaaslike besture, metropolitaanse en streeksowerhede.

- Die instelling van vier Departemente van Gesondheid.

\section{implikasies vir \\ Personeeladministrasie}

'n Bevoegdheid wat in die nuwe Grondwet as 'n eie saak gelys is, is personeeladministrasie maar steeds ingevolge die bepalings van enige algemene wet oor personeel in 
diens van die Staat. Die Staatdienswet sal derhalwe ook van toepassing wees op en ten opsigte van personeel wat in diens is van die Departemente van Gesondheid (eie sake).

Daar sal dus net een staatsdiens en een personeelstelsel wees sodat alle gesondheidspersoneel op dieselfde diensvoorwaardes, behandeling, regte en beskerming geregtig sal wees. Van die fundamentele beginsels onderliggend aan die personeelstelsel naamlik dié van meriete en doeltreffendheid sal egter nie afgewyk kan word nie. Waar amptenare van verskillende bevolkingsgroepe nouer met mekaar gaan saamwerk in die toekoms sal gesonde menseverhoudings steeds van deurslaggewende belang wees.

As gevolg van die nuwe Grondwet sal daar 'n groot verskeidenheid van plaaslike besture vir elk van die drie bevolkingsgroepe ontstaan. Daarbenewens maak die Wet op Swart Plaaslike Besture no 102 van 1982 voorsiening vir outonome Swart stadsrade waarvan daar reeds dertig ingestel is en meer in vooruitsig gestel word.

Om die nodige koördinasie te bewerkstellig wat betref salarisse van gesondheidspersoneel, diensvoorwaardes, opleidingstandaarde, bevorderingsmoontlikhede en mobiliteit van so 'n groot verskeidenheid van kategorieë van gesondheidspersoneel, is dit absoluut noodsaaklik dat daar indringend na die moontlikheid van 'n gemeenskaplike personeelstelsel gekyk word wat die personeel van plaaslike besture sal insluit. Die feit dat funksies, en daarmee saam noodwendig die kundige personeel, van die eerste en tweede vlak owerhede na plaaslike besture afgewentel sal word maak 'n gemeenskaplike personeelstelsel noodsaaklik.

Tans word salarisse van gesondheidspersoneel in diens van oorwegend Blanke plaaslike besture deur middel van onderhandeling tussen munisipale verenigings en munisipaliteite bepaal en in geval van geskille word dit na die Nywerheidsraad verwys. Enige aanpassings is nie onderhewig aan aanbevelings van die Kommissie van Administrasie nie.
Wat gaan die implikasie hiervan wees as outonome plaaslike besture vir Kleurlinge en Indiërs tot stand gaan kom in die nuwe bedeling. Die aandag word daarop gevestig dat Swart plaaslike besture onder heeltemal ander wetgewing tot stand kom met 'n eie stel personeelregulasies. Indien 'n gemeenskaplike personeelstelsel op hierdie stadium nie moontlik is nie sal daar aan 'n ander meganisme vir koördinasie van personeeladministrasie gedink moet word.

\section{Implikasies vir koördinasie}

Met die totstandkoming van nuwe strukture in die nuwe bedeling waar daar moontlik vier Departemente van Gesondheid sal ontstaan sal daar ingrypende veranderinge in die huidige stelsel van koördinasie en kontrole aangebring moet word, steeds met die ideaal van regering deur konsensus voor oë. Die huidige Nasionale Gesondheidsbeleids raad sal uitgebou moet word sodat dit aan die vereistes van die nuwe Parlement en nie net aan dié van die nuwe Volksraad sal voldoen nie.

\section{FINANSIËLE IMPLIKASIES}

Die sukses van die nuwe bedeling sal grootliks afhang van die doeltreffendheid van finansiële reëlings. In die nuwe Grondwet sal die finansiële en begrotingsproses steeds sentraal bly met net een fiskale owerheid. Die behoeftes van die verskillende gemeenskappe sal steeds meer aanspraak maak op die beperkte fondse. Koördinasie en beplanning van uitgawes en die identifisering van prioriteite sal 'n absolute vereiste wees en dit sal meebring dat groter finansiële dissipline aan die dag gelê sal moet word.

Tesourie sal in die nuwe bedeling fondse toeken vir die finansiering van algemene sake en ook toekennings aan die drie Huise van die Parlement maak. Daar sal 'n finansiële administrasie komponent vir elkeen van die drie Huise wees wat finansiële kontrole sal uitoefen oor eie sake. Daar sal gevolglik vier begrotings wees, een vir algemene sake insluitend oordragbetalings, en een elk vir die Huise.

Wat algemene sake betref sal begrotings soos in die huidige sisteem op departementele vlak, tesourie vlak en dan op kabinetsvlak, waar lede van al drie Huise teenwoordig sal wees, hanteer word. Toekennings vir eie sake sal so ver moontlik op 'n nie-politiese vlak hanteer word en sal daarna ook op Ministersraadvlak, op finansiële administrasievlak en op Departementele vlak hanteer word.

Die beginsels waarop die nuwe finansiële stelsel sal berus en wat besondere implikasies vir gesondheidsdienste inhou is dat daar net een fiskale owerheid sal wees wat ekonomiese beleid bepaal, dat die Huise nie belastingbevoegdhede sal hê nie, dat belastingsbronne verkieslik gemeenskaplik ontgin behoort te word en dat belastingsmagte en ook leningsmagte nie deelbaar sal wees nie.

Toekennings sal op 'n voorafbepaalde minimum standaard van diens moet berus en die behoeftes van elke bevolkingsgroep sal daaraan gemeet moet word. Enige verdere toekenning sal as 'n eksterne toekenning aan elke Huis voorsien word.

\section{Tipes toekennings}

Die Nuwe Grondwet (Artikel 84) onderskei tussen drie tipes toekennings en maak voorsiening vir die heffing van diensgelde.

\section{Statutêre toekennings}

Dit sal verseker dat die verskillende Huise in staat sal wees om 'n gesamentlike, vooraf bepaalde, minimum standaard van gesondheidsdiens ten opsigte van eie sake te kan lewer.

Dit word voorgestel dat die statutêre toekenning op "n normatiewe basis volgens ' $n$ formule bepaal moet word en wel op 'n basis van 'n minimum standaard van diens wat vooraf deur onderhandeling met die verskillende gemeenskappe bepaal sal moet word.

Hierdie formule sal gevolglik die behoeftes van die onderskeie gemeenskappe asook die relatiewe vlak van dienslewering in ag moet neem. Binne die land se finansiële vermoëns behoort daar na 'n eindbestemming, waar daar 'n geregverdigbare gelykheid van diensverskaffing sal wees, beweeg te word. 
Waar verskille bestaan, gemeet volgens minimum standaarde, sal dit noodwendig oor 'n lang termyn en in fases uitgewis moet word.

Die implikasies vir beplanners van gesondheidsdienste is voor die hand liggend. Ons het reeds 'n Nasionale Gesondheidsdienstefasiliteiteplan wat as norm vir die doel gebruik kan word en die daadwerklike toepassing daarvan sal groter momentum moet kry as in die afgelope aantal jare.

\section{Voorwaardelike Toekennings}

Hier word verwys na fondse wat benodig word vir die finansiering van addisionele kapitaaluitgawes of -projekte wat nie gedek kan word deur die kapitaalkomponent wat in die statutêre toekenning opgeneem is nie. As voorbeeld hiervan is die oprigting van 'n groot Gemeenskapsgesondheidsentrum (GGS 60) in ' $n$ snelgroeiende stedelike gemeenskap. Hierdie uitgawes kan uit eie fondse (diensgelde of heffings) verkry word of deur die Parlement vir die doel bewillig word.

\section{Supplementêre Ad Hoc- toekennings}

Bo en behalwe statutêre en voorwaardelike toekennings sal verdere toekennings aan Huise gemaak kan word vir finansiering van eie sake. Dit sal nie soos statutêre toekennings aan enige voorwaardes onderworpe wees nie maar sal in die Hoofbegroting deur die Parlement gesamentlik bewillig word.

\section{Diensgelde}

In paragraaf 11 (3) van Bylae 1 tot die Grondwet word voorsiening gemaak vir die oplê van heffings of diensgelde deur 'n Huis op dienste wat deur die betrokke Huis gelewer word. Dit is nie 'n belasting nie maar ' $n$ heffing wat op die verbruikers van 'n gesondheidsdiens geplaas word. Die betrokke Huis sal seggenskap oor hierdie inkomste hê. Daar moet egter vir hierdie inkomste begroot word in die begrotings vir eie sake in die betrokke Huise.

Die doel vir die voorsiening in die Grondwet vir die heffing van diensgelde is dat, indien die betrokke
Huis sou verkies om 'n hoër standaard van gesondheidsdienste as wat deur die minimum standaard of norm neergelê word, aan te bied, die betrokke Huis heffings op die verbruikers sal $k$ an plaas om dit te finansier.

Dit word in die vooruitsig gestel dat daar aanvanklik tog 'n mate van beheer oor uitgawes van sentrale vlak moet wees op fondse wat onvoorwaardelik aan Huise toegeken word. Fondse wat vir gesondheidsdienste toegeken word behoort byvoorbeeld nie vir onderwysdoeleindes aangewend te word nie.

\section{GESONDHEIDSDIENSTE PRIORITEITSBEPALING}

Die finansiële implikasies wat die nuwe Grondwet vir die lewering van gesondheidsdienste in die R S A inhou beteken derhalwe dat die realiteit van die Nasionale Gedondheidsdienste Fasiliteiteplan (NGFP), vir almal vir wie die welsyn van alle gemeenskappe op gesondheidsgebied erns is, terdeë besef moet word.

'n Stelsel van prioriteitsbepaling wat staatsoptrede ten opsigte van die lewering van gesondheidsdienste betref behoort op die volgende beginsels te berus:

- toenemende privatisering van owerheidsfunksies met betrekking tot gesondheidsdienste

- oorweging van langtermyn funksionele bestedingsimplikasies

- indien huidige beleid voortgesit word en

- indien NGFP norme doelbewus toegepas word

- groter klem op streekontwikkeling vanweë die geografiese, kulturele, etniese en sosio-ekonomiese verskille en behoeftes

- prioriteitstelling op die basis van die behoeftes van elke bevolkingsgroep

- in die beplanning en bestuur van gesondheidsdienste moet doelgerig daarna gestreef word om regeringsdoelwitte soos die Bevolkingsontwikkelingsprogram te bevorder.

Om aan die beginsels van die nuwe Grondwet te voldoen word die volgende langtermynbestedingsprioriteite vir die uitbouing van omvattende gesondheidsdienste

- vir alle bevolkingsgroepe aanvaarbaar sal wees en

- aan minimum standaarde sal voldoen

in volgorde van belangrikheid voorgestel:

- Die voorsiening van veilige drinkwater en basiese omgewingsdienste vir die hele bevolking teen die jaar 1990.

- Die voorsiening van primêre gesondheidsorgdienste aan alle bevolkingsgroepe deur middel van gemeenskapsgesondheidssentrums. As mikpunte behoort die volgende norme geneem te word:

- 'n maksimum kindermortaliteit van 50 per 1000 lewende geboortes teen die jaar 1990

- ten minste een gemeenskapgesondheidsentrum 10 per 10000 bevolking teen die jaar 1990 .

- Die voorsiening van gesinsbeplanningsdienste aan die hele bevolking van die $R$ S A met 'n geboortesyfer van nie hoër nie as 30 per 1000 vir alle bevolkingsgroepe as mikpunt teen die jaar 1990.

- Die doeltreffende koördinering van 'n Bevolkingsontwikkelingsprogram met die volgende doelwitte

- Verlaging van kindermortaliteit

- fertiliteitsbeheer

- 'n gemeenskapsontwikkelingsprogram

- sosio-ekonomiese ontwikkeling van gelyke omvang onder alle bevolkingsgroepe.

- Die beskikbaarstelling van die verskillende kategorieë van hospitaalfasiliteite.

Die volgende riglyne by die toekenning van fondse vir gesondheidsdienste tot die jaar 1990 wat sal voldoen aan die bogemelde prioriteite sal daadwerklike aandag moet geniet in die nuwe bedeling:

- Toenemende privatisering van gesondheidsdienste

- 'n Klemverskuiwing van kuratiewe dienste na voorkomende dienste. 
- Besondere aandag aan die uitbouing van gesondheidsdienste wat deur die plaaslike besture van al vier bevolkingsgroepe gelewer word om hulle in staat te stel om die mikpunte wat in die eerste vier prioriteite hierbo gestel is te kan verwesenlik.

- Die daarstelling van die nodige administratiewe strukture beman deur gesondheidspersoneel met die nodige bestuursopleiding om te verseker dat die bogemelde prioriteitsmikpunte bereik word.

\section{DIE UITDAGING}

Om aan die uitdagings wat die nuwe Grondwet aan gesondheidsadminis- trateurs stel die hoof te kan bied, sal gesondheidspersoneel op top, middel sowel as operasionele vlak oor die nodige bestuursvermoë moet beskik. Bestuursopleiding is van besondere belang vir alle senior gesondheidspersoneel. Dit is op ' $n$ Seminaar oor Bestuursopleiding reeds op 15 September 1983 in Bellville weer eens beklemtoon.

Om die nuwe bedeling te laat slaag sal daar ook besondere aandag aan gesonde menseverhoudings op alle vlakke en tussen alle bevolkingsgroepe geskenk moet word.

Ferdinand Deist sê in "Tussen Angs en Sekerheid": Ons as mense vervul twee soorte aktiwiteite. Sommige is interessant en ander is oninteressant. 'n Oninteressante spel laat by die oplossing van die probleem geen vrae meer oor nie. Dis 'n meganiese spel. Daar is bepaalde reëls wat jy moet nakom. Doen jy dit stiptelik werk die meganisme en word die foutlose en finale antwoord uitgespel.

'n Interessante spel daarenteen, is 'n spel wat by die oplossing van die gestelde vraag nuwe probleme laat ontstaan. Dis 'n skeppende spel. Dit lei voortdurend na nuwe vrae. As dit klaar gespeel is, bly daar altyd nog ruimte vir wonder.

\section{Vervolg vanaf p. 14}

Bygesê, hierdie desentralisasie sal nie lukraak of willekeurig geskied nie. Dit sal altyd gekoppel wees aan die sentrale punt waarvan die President aan die spits is. Dit lyk egter, dat ten einde doeltreffende bestuur te verseker, gedesentraliseerde streke noodwendig 'n nuwe klem sal ontvang. In 'n sekere sin is dit 'n proses wat reeds in Suid-Afrika aan die gang is. Wat oorbly, is beter en meer doeltreffende koördinering.

\section{Bedlngingspolitiek}

'n Derde implikasie is dat ons onherroeplik die era van bedingingspolitiek betree het. Die deelnemende groepe word in die nuwe bedeling in 'n posisie van bedinging teenoor mekaar geplaas. Soos die dominee gewoonlik by huwelikseremonies sê: Dit is 'n kwessie van gee en neem! Een groep sal nie alles kan gee of neem nie.

Dit kan verwag word dat hierdie bedinging nie net oor politieke regte en ander kwessies van 'n meer politieke aard byvoorbeeld die verwydering van diskriminasie, sal gaan nie. Finansies behoort hoog op die bedingingslys te staan. Om dit maar baie blatant te stel: groter pariteit in die besteding van staatsfondse ten opsigte van die bevolkingsgroepe sal 'n hoë prioriteit wees. Blankes sal moet verwag dat die opsny van die koek nie vir hulle sal bevoordeel nie. Die skrywer verwag dat onderwys, behuising en sosiale dienste by die nuwe vennote in die regering van Suid-Afrika groot voorrang sal geniet.

\section{Samewerkings- en same- sprekingstrukture}

'n Vierde implikasie, waarna reeds verwys is, is die ontstaan van samewerkings- en samesprekingstrukture op talle vlakke. Waar dit tans nog nie bestaan nie, sal dit geskep moet word

Wat die implikasies van die nuwe bedeling vir die deel van geriewe sal wees, is moeilik om te sê. ' $n$ Waarskynlike interpretasie is dat as riglyn sal geld dat eie geriewe 'n voorkeur sal geniet waar dit wenslik en finansiëel moontlik is. Korton, dit sal nie moontlik wees om vóóraf hieroor ' $n$ finale en waterdigte bloudruk te gee nie.

\section{SLOT}

Die volgende moet beklemtoon word:

- 'n Konstitusie reguleer die verspreiding en gebruik van mag. Politiek en regering hou immers primêr met mag en die uitoefening daarvan verband.

- 'n Konstitusie waarborg die regte van die burgery. Dit is die burgery se versekeringspolis teen willekeurige staatsoptrede.
- 'n Konstitusie waarborg 'n ordelike gang van sake en verseker stabiliteit.

Vereenvoudigd gestel kan ons sê dat politieke bedinging met ' $n$ spel vergelyk kan word. Vir die spel om ordelik te kan verloop, moet daar voorgeskrewe reëls en aanvaarde konvensies wees. Die spelers moet weet wat mag en wat nie mag nie.

Dit word nie betwyfel nie dat die nuwe konstitusie wel voldoen aan dit wat hierbo in die algemeen oor 'n konstitusie gesê is. Tog moet nog iets beklemtoon word. Die wyse waarop 'n konstitusie saamgestel is, is 'n belangrike voorwaar's vir sy sukses. Dit is ongelukkig nie al voorwaarde nie. 'n Ander ewe belangrike voorwaarde hou verband $\mathrm{m}^{\mathrm{r}} \mathrm{t}$ die vraag of die betrokkenes die konstitusie wil laat werk.

Die beeld van die spel word hier ter verduideliking toegepas:

reëls, belangrik soos dit mag wees, waarborg nog nie 'n vloeiende spel nie. Laasgenoemde hang veral af van die gesindheid van die spelers. As hulle wil, kan hulle ook afbrekend speel.

Dit geld ook vir die nuwe konstitusie: om daarvan 'n sukses te maak, sal die deelnemende partye in die regte gees en gesindheid daaraan moet deelneem. Hiervoor sal almal wat Suid-Afrika se belange op die hart dra, alles in die werk moet stel. 